\title{
Capturing learning: using visual elicitation to investigate the workplace learning of 'newly qualified' in-service teachers in further education
}

\section{Rachel Terry}

Huddersfield Centre for Research in Education and Society (HudCRES), Huddersfield, $U K$

r.terry@ hud.ac.uk

@ rachedu

Since 2017 Rachel Terry has been a Senior Lecturer in the School of Education and Professional Development at the University of Huddersfield. Previously she worked for 15 years in a Further Education college, first as an ESOL teacher then as a teacher educator. Her doctoral research explores the workplace learning of recently qualified in-service teachers in further education. 


\section{Capturing learning: using visual elicitation to investigate the workplace learning of 'newly qualified' in-service teachers in further education}

Unlike their counterparts on school-based Initial Teacher Education programmes, 'newly qualified' teachers in further education in England do not have the entitlement to support conferred by Newly Qualified Teacher (NQT) status. Yet there is an expectation that ITE providers support former trainees' progress in employment, with little recognition of the complexity of the sector or the influence of the workplace on their professional development. This article reports on a study investigating what former in-service trainees learn in the workplace in their first year after qualifying, with a view to better supporting this process. Learning is theorised as 'participation' in a socio-cultural practice, using a framework developed from Lave and Wenger. But the tacit, informal nature of much workplace learning makes it inherently difficult to operationalise, often going unrecognised by participants. The focus of this article is methodological, considering one strategy for addressing this issue, specifically the use of the Pictor technique (King et al. 2013). The contribution and limitations of this Visual Elicitation Method are evaluated using a small amount of interview data. The article concludes that this method has a valuable role to play in 'capturing' the learning of former trainees and in the study of workplace practices more broadly.

Keywords: Pictor technique; visual elicitation; teacher education; former trainee teachers; further education. 


\section{Introduction}

The recent policy context for trainee teachers in further education (FE) in England has been marked by moves towards increasing professionalisation and regulation, swiftly followed by deregulation (Tummons 2016, 347). Professional standards were introduced for teachers in the sector in 1999, revised in 2007 and again in 2014; yet the requirement for teachers to hold a teaching qualification, introduced in 2000, was followed within 12 years by the return to voluntary rather than compulsory qualification with the acceptance of Lord Lingfield's recommendations (2012). This runs counter to developments in other countries, where there is an increasing focus on ensuring that teachers in vocational education hold formal teaching qualifications (Brennan Kemmis and Green 2013, 103). Although the number of trainees studying a higher-level teaching qualification (Level 5 or above) stabilised to some extent between 2012 and 2015 following a significant drop in 2012 (ETF 2018, 25), the onus for gaining this has shifted firmly to the individual, with employers being less likely to support their employees, either financially or otherwise, in achieving this. The structure and formality of teaching qualifications such as the Certificate in Education (designed for those who have a vocational qualification in their specialist subject at Level 3 on the Qualifications and Credit Framework) or PGCE (for degree level entrants) offered by Higher Education Institutions is not echoed in the structures in place to support the achievement of these in the workplace, despite their significant work-based elements (Maxwell 2014).

The focus of this paper is the methodological implications of researching the learning of 'newly qualified' teachers in this sector, and the use of one methodological tool to address these. The inadequacy of a turbulent and often chaotic sector in supporting the development of trainee teachers has been highlighted in the literature, 
both in relation to pre-service trainees on placement (Avis and Bathmaker 2006; Dixon et al. 2010) and in-service trainees who are already employed, either in a paid or voluntary capacity, while completing their qualification (Maxwell 2014). This environment has been shown to encourage the development of coping strategies rather than pedagogical knowledge and skills (Orr 2012). The implications of this context for teacher development beyond the achievement of the initial teaching qualification have not been widely explored, particularly in relation to former in-service trainees (FTs). This is despite the fact that a process of 'professional formation' in the workplace is required in order to achieve fully qualified status (QTLS) (SET 2018, 1); and despite the current expectation from the regulatory body Ofsted that FTs are tracked and supported by providers of Initial Teacher Education (ITE) in their progress in employment following qualification (Ofsted 2015, 8). It is significant that the same expectation applies across ITE, whether it takes place in schools, which have established structures for supporting Newly Qualified Teachers (NQTs), or through pre- and in-service programmes in FE. Given that many in-service FTs are employed by the same organisation before, during and after completing their part-time ITE course, it is the organisation, rather than the ITE provider, that has the most significant impact on their subsequent progress as a teacher.

This complex and potentially contradictory climate provides not only the context but also the motivation for the study reported in this article, an investigation of the workplace learning of in-service FTs attached to one university in the North of England. The study aims to better understand how the inter-relationship of individual, institution and policy context shapes the learning of FTs in their first year after qualification, with a view to suggesting ways in which this might be better supported. These 
understandings may also contribute to debates around the on-going development of teachers in FE beyond initial teacher education.

The focus of this article, however, is on the methodology adopted in the study and specifically the tools that may allow these understandings to be reached. It starts by justifying the chosen methodological approach with reference to the research questions and existing literature on workplace learning; it then sets out a conceptualisation of learning and how this is operationalised in the study; it goes on to consider the potential contribution of Visual Elicitation Methods (VEMs) and focuses on a specific example, the Pictor technique (King et al. 2013), through the analysis of a small amount of interview data; to conclude, the strengths and limitations of this VEM are discussed in relation to the task of 'capturing' learning and its wider potential for exploring educational practices in other contexts.

\section{Methodology}

As the focus of the study is how policy shapes the experience of the individual, a qualitative approach is adopted, intended to explore the 'subjective meanings' that observable behaviour may hold for those involved (Pring 2000, 98). Yet the complex inter-relationship between personal understandings and 'underlying structural mechanisms' (May 2001, 12) leads to a critical realist approach, in which the perceptions and interpretations of individuals are valued as windows on reality, but it is not assumed that they offer a transparent 'pane' or that there is a single acceptable viewpoint. The researcher's own ways of describing the world and of creating knowledge are similarly subject to critique (Scott 2010, 13). For the individual is regarded as part of a social world in which structure and agency are closely intertwined. This requires a methodology that allows a productive tension to be maintained between the 'affordances' of the social environment (Billett 2002) and the subjective experiences 
of the individual. This is offered by a case study design (Yin 2009, 50), a key advantage of which is its capacity to provide a holistic view of the individual within their wider context, even where the boundaries between 'phenomenon' and context are unclear (ibid., 18). The characteristic use within a case study of multiple methods further allows the different levels of context (individual, institutional and national/international) to emerge and interact (ibid., 11).

The boundaries of the case itself are marked by the former trainee's achievement of one of a suite of higher level ITE qualifications (Certificate in Education, Professional Graduate Certificate, Postgraduate Certificate or Postgraduate Diploma in Education) as part of the collaborative provision of one university. They are further delimited by the research questions, which establish a focus on: further education in England; the workplace context; former in-service trainee teachers; and the current policy context. Temporal parameters are imposed by the second research question which limits the length of research interest to the first year after qualification.

\section{Research questions:}

1) How does the institutional and policy context for teachers qualifying via the inservice route in the further education sector in England shape the learning of former trainees?

2) What do former trainees learn in their first year after completing their formal qualification? How do they learn this?

3) How may the relationship between the learning of former trainees and the institutional and policy context be theorised?

As these research questions show, the focus of the case is the theoretical issue of how learning takes place within an institutional and wider policy context, making this an 'instrumental' case study (Stake 1995). It is also 'collective' (Stake 1995, 3), in that the 
'sample' consists of eight FTs who completed their qualification at three different FE colleges. These FTs are further spread across 6 different workplaces, including FE colleges, schools and a private training provider. They were selected purposively to gain a diverse picture of the case, although difficulties in recruiting participants meant that decisions about who to include were also pragmatic.

A crucial dimension of the research design is its ability to investigate learning. This is not understood in a normative sense, although the ITE qualification could certainly be regarded as embodying value judgments around what it is desirable to learn and what constitutes 'effective' learning (Biesta 2009, 35). The focus here is on what FTs actually learn in the workplace, rather than what they are expected to learn or even what they think they are learning. As Wenger famously asserts: 'even failing to learn what is expected in a given situation usually involves learning something else instead' $(1998,8)$. But extant research into workplace learning shows that identifying this type of non-formal learning in practice is highly problematic, precisely because it is not generally recognised by those who are the subject of it. Furthermore, this often tacit learning does not accord with the 'standard paradigm' (Beckett and Hager 2000) of learning prevalent in the dominant discourse (Eraut 2004, 249), where learning is viewed primarily through the metaphor of 'acquisition' (Sfard 2010, 5) and therefore: 1) distinct from the individual engaging in it; 2) separable from the context in which it takes place; and 3) open to measurement. To view learning as primarily 'situated' in its context, occurring not just in but through its social setting, requires a different approach to its operationalisation, one which will form the subject of the next section.

\section{Operationalisation of learning}


Finding appropriate methodological tools for researching learning relies first on a clear conceptualisation of what this is understood to be. A significant reference point in this context is Lave and Wenger's Situated Learning (1991). The authors adopt a social practice approach to learning, viewing it as integral to the process of engaging in social activity. It is relational in nature, indeed 'agent, activity, and the world mutually constitute each other' (33), echoing Marxist understandings of the dialectical and historical nature of the social world. When we act, our actions are shaped by past historical practices and serve to shape future possibilities for action. In the context of workplace learning, the workplace 'invites and structures individuals' participation in work' which simultaneously 'shapes the kind and quality of their learning' (Billett 2002, 38). This relational interplay is evident in Wenger's formulation of a social theory of learning, where learning occurs through four 'deeply interconnected and mutually defining' elements (Wenger 1998, 5): community, identity, practice and meaning. The focus of this study is not on the role of communities of practice, although this concept has been widely applied (and critiqued) in the context of workplace learning (Boud and Middleton 2003; Fuller et al. 2005; Hughes, Jewson and Unwin 2007) and since extended (Wenger-Trayner et al. 2015). Nor is its focus explicitly on identity formation or 'learning as becoming' (Wenger 1998, 5), even though this has been shown to be pertinent to vocational learning (Colley et al. 2003). Instead the study foregrounds the elements of practice and meaning, on the basis that they offer valuable theoretical lenses through which to view the concept of learning. Practice is defined here as a 'process by which we can experience the world and our engagement with it as meaningful' (Wenger 1998, 51). Experiencing the world as meaningful enables us to participate in it. But meaning is never fixed, as it involves the interaction of two processes, those of participation and reification (ibid., 55), the latter referring to the 
physical or textual traces left by our participation. This inter-relationship of elements can be expressed as a triangle where learning is defined as the negotiation of meaning necessitated by participation in practice (see figure 1).

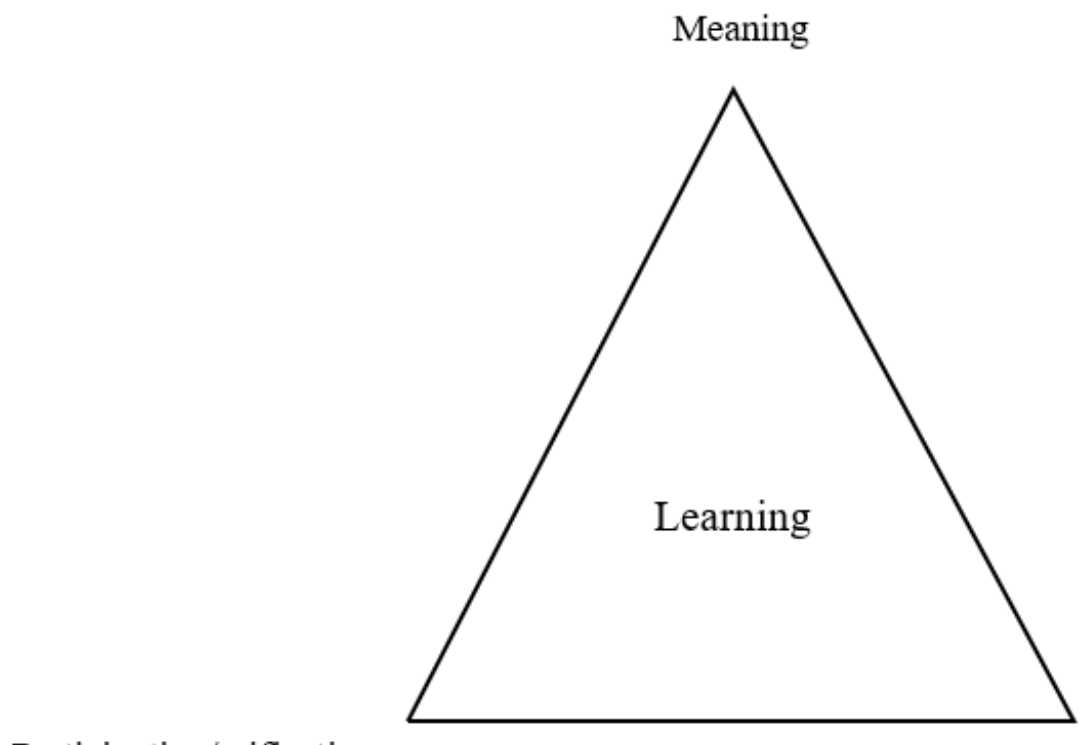

Participation/reification

Practice

Figure 1. Definition of learning, drawing on Wenger's social theory of learning (1998)

To illustrate this model using an example from the context of this study, the FE teacher engaging in a tutorial with a student is participating in the accumulated web of practices which surround 'tutorials' in their organisation and beyond, such as expectations around the roles adopted by teacher and student and the type of issues discussed; these practices may be reified through the 'paperwork' or online records they produce, such as signed learning contracts or entries in 'Promonitor ${ }^{\mathrm{TM}}$ '; unless these practices are experienced as meaningful, in the sense of being understood by the participants, participation will be impaired. The drive to experience these practices as meaningful involves the participants in a process of negotiating meaning. Although 
perhaps perceived as a mundane aspect of their everyday practice by both teacher and student, this negotiation of meaning is also a process of learning.

This example points to the operationalisation of learning in the study.

Addressing the research questions involves gaining insights into the practices in which the FT participates, for example, teaching, planning, talking to others, or engaging in formal CPD; it also involves investigating the forms this participation takes and the reified artefacts it generates or uses, such as Schemes of Work, timetables or programmes of staff development; finally, it involves identifying the process of meaning-making in which the FT is engaged, which may be visible in their attempts to understand, define or question their experience as a recently qualified teacher. The methods used to address each of these points are illustrated in table 1, along with a justification of their selection.

Table 1. Operationalisation of learning (adapted from Mason 2002, 30)

\begin{tabular}{|l|l|l|l|}
\hline $\begin{array}{l}\text { Dimension of } \\
\text { learning }\end{array}$ & Example & Method & Justification \\
\hline Practice & $\begin{array}{l}\text { Teaching } \\
\text { Planning } \\
\text { Talking to colleagues } \\
\text { CPD }\end{array}$ & $\begin{array}{l}\text { Semi-structured } \\
\text { interviews }\end{array}$ & $\begin{array}{l}\text { Semi-structured } \\
\text { interviews provide } \\
\text { insights into activities } \\
\text { FTs have participated in } \\
\text { (whether perceived as } \\
\text { learning activities or not) } \\
\text { and who they have } \\
\text { interacted with. }\end{array}$ \\
\hline $\begin{array}{l}\text { Participation/ } \\
\text { reification }\end{array}$ & $\begin{array}{l}\text { The act of engaging in } \\
\text { the practices } \\
\text { above/artefacts } \\
\text { generated by this } \\
\text { participation e.g. } \\
\text { Schemes of Work, } \\
\text { timetables, meeting } \\
\text { records, staff } \\
\text { development materials }\end{array}$ & $\begin{array}{l}\text { Semi-structured } \\
\text { interviews } \\
\text { analysis }\end{array}$ & $\begin{array}{l}\text { Interviews provide } \\
\text { insights into how FTs } \\
\text { have participated and } \\
\text { their perceptions of this } \\
\text { process. }\end{array}$ \\
& $\begin{array}{l}\text { Document } \\
\text { Document analysis offers } \\
\text { another direction from } \\
\text { which to approach the } \\
\text { FTs' participation, i.e. } \\
\text { via its reified forms. }\end{array}$ \\
\hline
\end{tabular}




\begin{tabular}{|l|l|l|l|}
\hline $\begin{array}{l}\text { Negotiation } \\
\text { of meaning }\end{array}$ & $\begin{array}{l}\text { Knowing how to } \\
\text { participate } \\
\text { Making sense of } \\
\text { experience } \\
\text { Defining terms }\end{array}$ & $\begin{array}{l}\text { Semi-structured } \\
\text { interviews }\end{array}$ & $\begin{array}{l}\text { Interviews operate on } \\
\text { two levels: 1) shed light } \\
\text { on negotiation of } \\
\text { meaning involved in } \\
\text { participation in practices } \\
\text { identified by FTs; 2) } \\
\text { require negotiation of } \\
\text { meaning within } \\
\text { interview situation itself. }\end{array}$ \\
& & & \\
\hline
\end{tabular}


While observation of FTs in the workplace might appear to offer a further, potentially more direct way of identifying the practices in which they participate, this was rejected for the following reasons: first, the presence of an observer in a teaching session, for example, or as witness to an informal chat with colleagues, would inevitably have influenced what was being observed, potentially distorting the everyday practices that are fundamental to the study (Patton 2002, 306); second, observation has strong associations for FTs both with 'performance measurement' (Springbett 2015, 94) and with the practices of the formal ITE qualification, echoing the unequal power relationship between teacher educator and trainee, which in my dual role as researcher and teacher educator I was keen to minimise; third, many of the practices in which FTs participate, such as responding to emails or planning sessions are not easily accessible to an observer. Semi-structured interviews, meanwhile, offered the opportunity not just to identify the practices in which the FT participated, but the subjective meanings that these held for the FT, even as these were constructed through the interview interaction itself.

There remained a danger, however, that interviews would produce only generalised accounts of the FTs' practices, failing to pinpoint specific elements of their participation that were pertinent to their learning in the workplace context (Eraut 2004, 249). This might be in part because these elements were not perceived as relevant by the participant, or because the 'hegemonic discourses' (Chase 2011, 422) operating in their context served to constrain what they chose to talk about. For this reason, visual interviewing techniques were adopted, as considered in the next section.

\section{The Pictor technique}


Visual Elicitation Methods (VEMs) refer to the use of visual images made either by the participant or the researcher as part of the research process to prompt talk, generally in an interview situation. Rose identifies many advantages of their use (2016, 315): they may prompt talk about different things, including places that researchers are not able to go; they have been shown to generate different kinds of talk, including talk that is more emotional and affective in nature; they also serve to empower participants by giving them increased control over what they talk about. The participant is positioned as an 'expert' in relation to the interview content. These benefits are reinforced by Banks, who discusses the power of photographic elicitation in semi-structured interviews, asserting that photos can give vague references 'sharpness and detail' $(2007,65)$, and, furthermore, ease the interview process by playing the role of a 'neutral third party' which can be looked at or talked about (ibid., 65).

One such visual elicitation method is the Pictor technique, developed by Nigel King and others as a tool for exploring relationships in collaborative working, primarily in healthcare settings (King et al. 2013). The technique was designed to draw out the complexities of collaborative working, revealing elements or key 'players' that might otherwise be overlooked. It also sought to go beyond the "official' explanations' professionals might present, because of their implicit knowledge of how things were supposed to work (King et al. 2013, 1139). The Pictor technique does this by asking the participant to represent the key agents (people or things) involved in a specific case by writing each one on a sticky arrow (with a choice of three colours). The participant then places these where they see fit on a large piece of paper, having been advised that they may use the placement of the arrows to suggest the relationship(s) between them. The resulting chart is used as an interview prompt: for example, 'tell me about what you have done here'. While there are other related types of graphic elicitation, such as eco- 
mapping or social convoy diagrams (Bravington and King 2018), Pictor appeared wellsuited to the research questions because it is a relational technique, exploring not just the relationship between the participant and other people/things, but allowing the interconnections between other elements to be considered. Although relationships are not explicitly investigated in the study, its focus is nonetheless relational, in that the learning of FTs is placed firmly within the institutional and wider policy context (RQ1 and RQ3), and, as the prior conceptualisation of learning indicates, viewed as occurring through the participation of the individual in social practice. The Pictor technique therefore appears well suited to the exploration of this social dynamic.

The Pictor technique was used as one element of semi-structured interviews carried out with FTs, first near the start of their first academic year after qualifying and again towards the end. The question was posed: 'Who or what influences what you do in your job role?', with accompanying written guidance suggesting that this might include people, groups of people or organisations, and other factors or 'things'. In the second interview, they were asked to return to their initial chart and consider if/how their response to the question might have changed and to adapt the chart accordingly, introducing a longitudinal element. This process was used as a prompt for talk, rather than as a source of visual data, although comparison between charts can be revealing (King et al. 2013, 1148). Initial Pictor interviews were carried out with eight FTs, and follow-up interviews with seven of these, generating a significant amount of spoken data. At this stage in the research and for the purposes of this paper, I consider the analysis of one chart and its accompanying spoken data, using this as a worked example of how this visual tool might contribute to my grasp of what a FT learns in the context of the workplace. A second Pictor interview with a different participant is used to consider the potential limitations of the tool. This initial analysis, conducted before the 
data set is analysed as a whole, serves the function of testing out my methodology and suggesting areas where this might need to be revised or adapted. Any findings at this stage are highly tentative, as analysis has not yet been carried out of the remaining data or viewed in conjunction with data from other sources.

\section{Analysis of the data}

The central feature of data deriving from a Pictor interview is that it is in two parts: the visual chart and the spoken data associated with this. King et al. (2013) stress the importance of 'moving iteratively' (1147) between the two in the process of analysis, allowing the participant's explanations to inform our understanding of the chart and vice versa. On a practical level this involves listening to and working with the transcribed spoken data with a copy of the chart to hand. While King et al. give examples of finding interesting points of comparison between participants' charts, they caution against interpreting the visual data in isolation, as this may lead to ascribing meaning in a way that is contradicted by the spoken data (1148).

The type of analysis conducted will depend on the theoretical and methodological approach adopted in the study (King et al. 2013, 1147). Here thematic analysis was used to relate the data to the research questions and identify emerging themes. Although $a$ priori themes were established deriving from: 1) the research questions; 2) the theoretical framework (in particular, the conceptualisation of learning); 3 ) the literature; and 4) my own experience as a former FE practitioner, as set out in table 2, many of these were ultimately found to be too broad to provide a meaningful framework for analysis. 


\begin{tabular}{|c|c|c|c|}
\hline $\begin{array}{l}\text { From research } \\
\text { questions }\end{array}$ & $\begin{array}{l}\text { From theoretical } \\
\text { framework }\end{array}$ & From literature & From experience \\
\hline $\begin{array}{l}R Q 1 \\
\text { Role/perceptions } \\
\text { of: institutional } \\
\text { context; policy } \\
\text { context. } \\
\text { Position as } \\
\text { recently qualified, } \\
\text { in-service teacher } \\
\text { - role/perceptions } \\
\text { of ITE } \\
\text { qualification. } \\
R Q 2 \\
\text { Learning - what? } \\
\text { How? } \\
\text { (RQ3 } \\
\text { To be answered } \\
\text { through } \\
\text { subsequent } \\
\text { analysis). }\end{array}$ & $\begin{array}{l}\text { Learning as negotiation } \\
\text { of meaning necessitated } \\
\text { by participation in } \\
\text { practice- alert to: } \\
\text { Practices; } \\
\text { Participation/reification; } \\
\text { Negotiation of meaning. }\end{array}$ & $\begin{array}{l}\text { Policy } \\
\text { 'enactment' } \\
\text { (Braun, Ball, } \\
\text { Maguire \& } \\
\text { Hoskins 2011) } \\
\text { Tacit/informal } \\
\text { learning (Beckett } \\
\text { \& Hager 2002; } \\
\text { Eraut 2004) } \\
\text { 'Affordances' for } \\
\text { learning (Billett } \\
\text { 2002; Maxwell } \\
\text { 2014) } \\
\text { 'Coping' (Orr } \\
\text { 2012) }\end{array}$ & $\begin{array}{l}\text { Impact of } \\
\text { workload. } \\
\text { Tensions between } \\
\text { management } \\
\text { expectations and } \\
\text { experience 'on } \\
\text { the ground'. } \\
\text { Tensions between } \\
\text { 'success' data } \\
\text { and 'learning'. } \\
\text { Value of self- } \\
\text { directed as } \\
\text { opposed to } \\
\text { mandatory CPD; } \\
\text { generic vs. } \\
\text { contextualised } \\
\text { CPD. }\end{array}$ \\
\hline
\end{tabular}

The following analysis prioritises the second area of a priori themes, that of the theoretical framework, in accordance with the focus here on 'capturing learning'. Given the study's situated understanding of learning, however, it is to be expected that each area of this framework (practice, participation/reification and meaning) runs through every other thematic strand.

In response to the question 'Who or what influences what you do in your job role?' Leah (not her real name) produced the Pictor chart reproduced in figure 2. Leah is a childcare lecturer within the Health and Social Care department of a medium-sized FE college in a formerly industrial town in the North of England. At the time of the interview she had worked at the college for 8 years, first as a placement officer supporting the childcare team, then for the last 3 and a half years as a lecturer. During 
her time at the college she had completed a BA in Early Years and then the in-service PGCE. She identified strongly as a member of the caring professions, positioning herself and other members of her team as people who primarily wanted to help others.

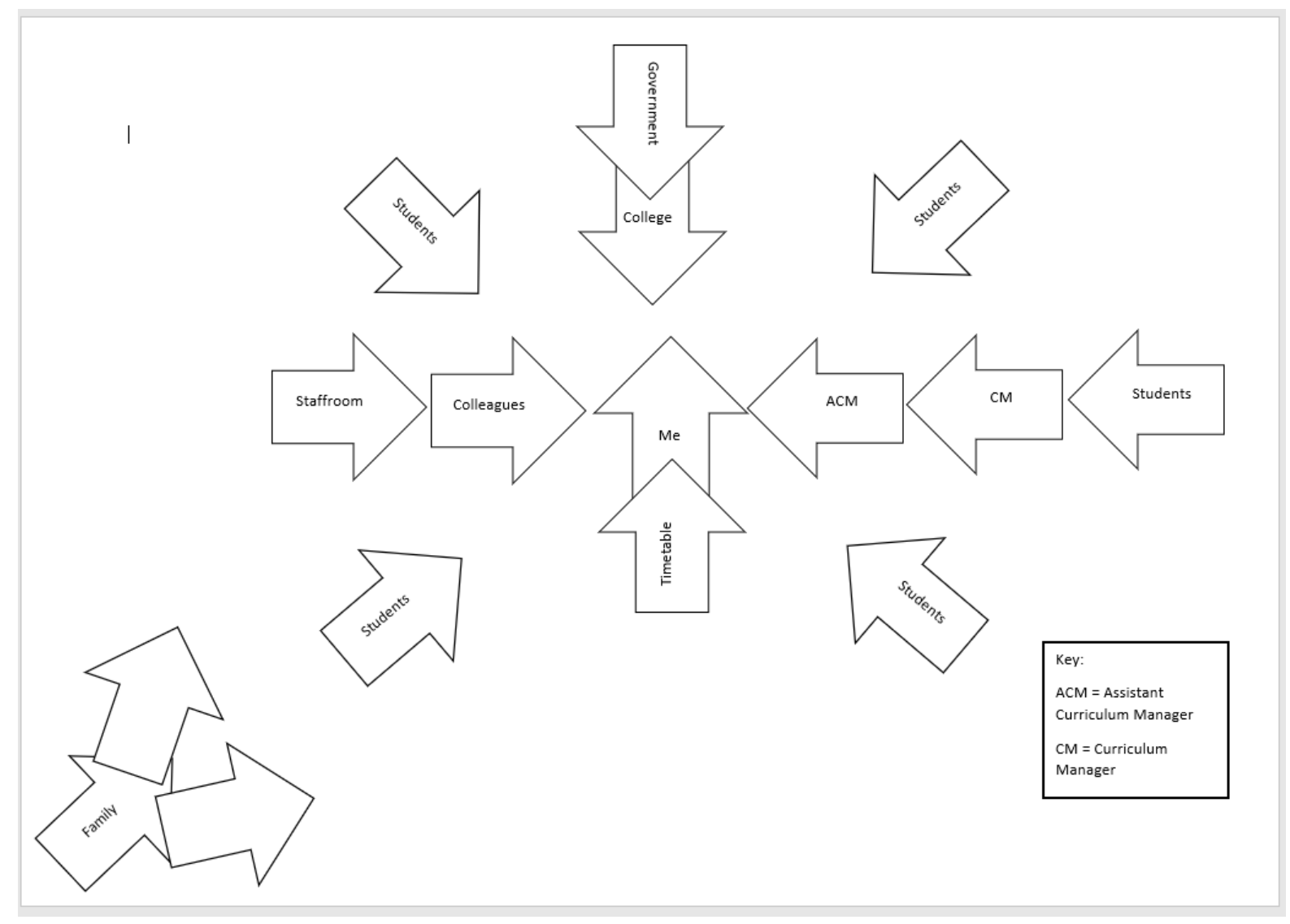

Figure 2. Leah's Pictor chart

An initial inspection of the Pictor chart suggests a range of practices in which Leah participates. These include the teaching responsibilities conveyed by her timetable, as well as interactions with colleagues, managers (Assistant Curriculum Manager and Curriculum Manager) and students. The position of the timetable arrow is particularly striking in that it partially covers the central 'me' label. The timetable and staffroom arrows also indicate the ways in which participation may appear in reified form, the written layout of the timetable representing Leah's working week, while the physical reality of the staffroom is identified as an influencing factor beyond the people who populate it. The arrows all point inwards towards the 'me' arrow, and there is 
symmetry in their layout and in the colours chosen (not reproduced here), suggesting a cohesive view of the workplace context. Students point inwards from all directions, perhaps conveying the influence they exert on the practices represented in the centre. The government and college are placed in a hierarchical formation at the top of the chart, suggesting a 'top down' view of the management and policy structures. Family, meanwhile, sits on the edge of the main frame, two blank arrows radiating outwards from it. As warned against above, analysing the chart in isolation in this way runs the risk of reaching invalid interpretations of the data. When asked about the significance of the choice of colours, for example, Leah just states that she 'liked' them. The colour groupings could, of course, still be representative of underlying cognitive structures of which the participant is not fully aware; but this interpretation would need to be approached with caution and explored in conjunction with the explanations that the participant does provide.

The position of the timetable emerges through the spoken data as highly significant. Leah explains:

I've put myself and the timetable together cos that's what I have to do, what you have to do, you know you have to stick to your timetable and that's what, that's what you're doing

The timetable arrow is placed in such close proximity to herself because it is almost synonymous with her role. This is not just an individually prescribed practice but something she regards as common to all teachers in her position, as subtly conveyed by the shift from the first person pronoun 'I' to the generic 'you'. An unidentified force appears to demand the acceptance of this reality, suggested by the repetition of 'have to' and ultimately 'that's what you're doing'. Colleagues are placed near to the centre for different reasons:

And then I've put my colleagues near to me because they're the ones who I ask for advice, who ask me for advice, who we bounce off with each other, 
who help if you need some help, who you can laugh with who you can cry with, $[\ldots]$ who are there for you really and actually know what you're going through on a day to day basis. They're the ones who understand, aren't they?

Here their proximity represents both their centrality to Leah's everyday experience and their emotional proximity. They are not just people who are encountered frequently in the staffroom but a crucial source of emotional support that enables Leah's ongoing participation in all the other elements of her role. Leah's appeal to the interviewer ('They're the ones who understand, aren't they?') is telling. It conveys the assumption that I will share her perception of their importance, perhaps as any FE teacher might. It also suggests an appeal for confirmation of her judgment, a negotiation of the meaning she can draw from her impromptu analysis.

While this interpretation of the role of colleagues in relation to her job role is very benign, the position of students is more contradictory. On a literal level she explains that she has included 5 arrows with the label of 'students' because she teaches 5 different courses. But when interpreting the placement of these arrows she states:

I've got them coming from all directions because that's what it's like, you, wherever you are, whether you're in the staffroom, whether you're in the refectory, whether you're in the library, on the stairwell, you can get asked questions, you can get asked for help, [...] so they're coming from all directions, which is fine, that's what we're here to do, we're here to, if it weren't for the students we wouldn't have a job, you know, that's what we're here to do. But I have put 5, just to represent the 5 courses that I'm teaching on.

This interpretation provides a telling insight into her experience of the college environment. It is clear that one of the practices in which she engages is responding to students' needs and queries, wherever and whenever these may emerge. But more significant is the tension evident between the pressure that this responsiveness places on the individual and the perception that this must be accepted as a necessary part of the role. The wider discourse of a policy context in which funding is dependent on student 'success' and of job insecurity across the sector is echoed in Leah's repetition of the 
mantra 'if it weren't for the students we wouldn't have a job'. But her avowed acceptance of this is tempered by the fact that they are 'coming from all directions' on her chart.

A similar tension is evident in her relationship with the college leadership, represented on her chart by the arrow 'college'. The top-down structure suggested by her chart is reinforced in her explanation of it:

at the top I've put the government and then underneath that I've put the actual college, and within that college, you've got your hierarchy, you've got your principal and vice principals, assistant principals and what they say goes, that's what you have to adhere to.

This unproblematic acceptance of the management structure becomes more nuanced when asked by the interviewer if she would ever deviate from the prescribed line:

So you might get a directive from the assistant principals [...] 'why have so many learners not attended GCSE?' [...] but you need to take into account the issues that the learners might be having, the responsibilities that they might have, and it can have an effect and it's not as easy as them sometimes coming in every day [...] it's not as cut and dry. I do sometimes think they forget that. But then, they are here to learn, they've enrolled on a course, they're here to learn so I'd never ignore it, but I think I can sometimes word it in a more nurturing way, in a more positive way.

Whilst accepting that the senior managers have valid reasons for pursuing the question of attendance in GCSE classes, Leah mediates their message when communicating with students. Her top-down understanding of the institution ('You might get a directive') comes up against her strong awareness of the 'bottom-up' pressures and complexities of the students' lives ('it's not as cut and dry'). But she works hard to reconcile these two dimensions, doing the job of enacting government policy in a way which aligns with the values of her profession ('nurturing'; 'positive') and which meets the institutional objectives by keeping the students on board.

This initial analysis suggests that part of what this former trainee is learning as she commences her first year after qualifying is how to navigate the tensions inherent in 
her position as a teacher. She is involved in the difficult task of establishing what does and does not form part of her role, and ultimately what type of teacher she wants to be. This is not a technical process of checking job descriptions or timetabled hours but an affective process of seeking to reconcile her own beliefs and assumptions with the practical demands of her daily experience and the institutional and policy discourse which seeks to impose its own managerial perspective, to which she partly subscribes. The next section will consider the basis on which I am able to make this analysis, considering the affordances and limitations of the Pictor technique in relation to the theoretical issue of investigating learning.

\section{Discussion}

This section returns to the conceptualisation of learning established above and considers to what extent the preliminary analysis of a limited amount of data suggests that the Pictor technique is able to address the study's research questions: what are the affordances and limitations of this visual tool in relation to the task of 'capturing learning'? The three dimensions of the working definition of learning set out above are considered in turn.

First, in relation to practice: the requirement to assign labels to elements of her job role appears to encourage the participant to identify and talk about activities that she might otherwise pass over. This is perhaps akin to Goodley et al.'s observation of the need for ethnographic research, particularly that conducted by practitioners, not just to work towards the goal of 'making the strange familiar' $(2004,56)$ but to make 'the familiar strange' (57). While this is not an ethnographic study, it is one in which the researcher shares to some extent the participants' insider knowledge of the research context, with the danger that obvious but important elements of this may be overlooked 
(Mannay 2016, 31). The Pictor task approaches questions posed in the semi-structured interview from a different direction, potentially enabling less idealised versions to emerge (King et al. 2013, 1139). When asked in the initial stage of the interview, before commencing the Pictor task, 'what have you done today?', Leah refers solely to the lesson she has taught: 'I had my course, so I had my level 1 learners [...] And that's it'. This is the institutionally sanctioned element of her job role, as formalised on her timetable. Further prompting ('Is there anything else that you've done today?') leads her to refer to an incident with a student, a topic which reappears in the Pictor task. In this way the data produced by the semi-structured interview and the visual elicitation task supplement each other, allowing a deeper exploration of their significance.

But it is also important to consider the possible threats to validity posed by the tool, as it is employed in this study. In relation to practice, the very requirement to identify influences on her job role, as prompted by the Pictor question, may lead the participant to label elements that are not especially significant, just in order to comply with the expectations of the task or to satisfy the researcher. The written guidance given to participants prior to completion of the task is intended to clarify and support the activity, yet there is also a danger that it may over-inform the resulting chart. It gives examples of people and things that might be included, stating: 'These may be concrete objects or places ('My staffroom'), abstract factors ('My timetable') or bigger influences such as specific policies or procedures ('The Sainsbury Report', 'Staff development policy').' When these items appear as labels on the chart, therefore, they may represent an artefact not so much of the participant's practices as of the Pictor task itself. A consideration of the eight initial charts produced within my study indicates that colleagues appear in some form in each of the charts, while the timetable appears in six. But the Sainsbury Report is named in only one, while family (not mentioned in the 
written guidance) features in three. This quantitative analysis suggests that the written guidance may shape the participants' responses but it does not determine them. The qualitative analysis of the spoken data, however, provides a more significant counter to the possible distortion of the findings by the tool.

Pictor charts are not analysed in isolation from the spoken data they generate; instead, the researcher plays an active role in interpreting the visual data in conjunction with the interview talk, the primary function of the visual artefact being to prompt the participant's explanations. This guards against a second potential limitation of the Pictor tool: that its focus on relationships encourages participants to seek connections where they are not present or significant. Pictor was selected as a relational diagramming technique precisely because it enabled the representation of 'associations between people or concepts' (Bravington and King 2018, 6). The question posed ('Who or what influences what you do in your job role?') assumes that carrying out the job involves interaction with other people, an understanding of the workplace context made explicit in the research questions and the conceptualization of learning adopted in the study. The use of the spoken data to inform and counter understandings suggested by the chart can be illustrated through consideration of the Pictor interview carried out with a second participant, Kerry, presented here for the purpose of addressing questions of validity in relation to the tool. It is indicative both of the practices she engages in and the process of participation/reification that they connote.

Kerry is a lecturer in Animal Care at the same FE college as Leah. She was also part of the same ITE cohort, completing her Certificate in Education in 2017. With little formal education in her childhood, she came to the college as an adult to complete Level 2 and Level 3 qualifications in maths, English, and Animal Care. This enabled her to take on the role of technician within the Animal Care department, where she carried 
out voluntary teaching hours in order to complete her ITE qualification. This led in turn to a paid teaching position alongside her technician role, and ultimately a full-time teaching post by the time of the first interview.

Kerry's Pictor chart is strikingly different from Leah's (figure 3). Arrows are lined up in three rows and placed approximately the same distance apart, the relationships between the labels not immediately apparent. In common with three out of the eight charts produced in this study, it exhibits a linear rather than a centrally organised structure. If considering the chart in isolation, this suggests that the tool has not generated the level of relational complexity intended by the researcher. Indeed, Bravington (as cited in King et al. 2013, 1149) identifies three features of a 'classic' Pictor chart, drawn from her analysis of instances where the method appears to have worked best. A 'classic' chart is: case specific, the participant encouraged to focus on their experience of a single, identified case; interrelational, the arrows indicating relationships between agents within the case; and complex, including a diverse range of people and types of relationship. On initial analysis, Kerry's chart appears to fall short against these criteria. Even Leah's chart, which is more interrelational in nature, does not focus on a specific event or experience (as the question does not demand this) and is not especially complex. However, in both cases the participant is able to provide a fluent explanation of their choice of labels and their placement of these. The reification of practices indicated by the chart becomes representative through the spoken data of active and complex participation. 


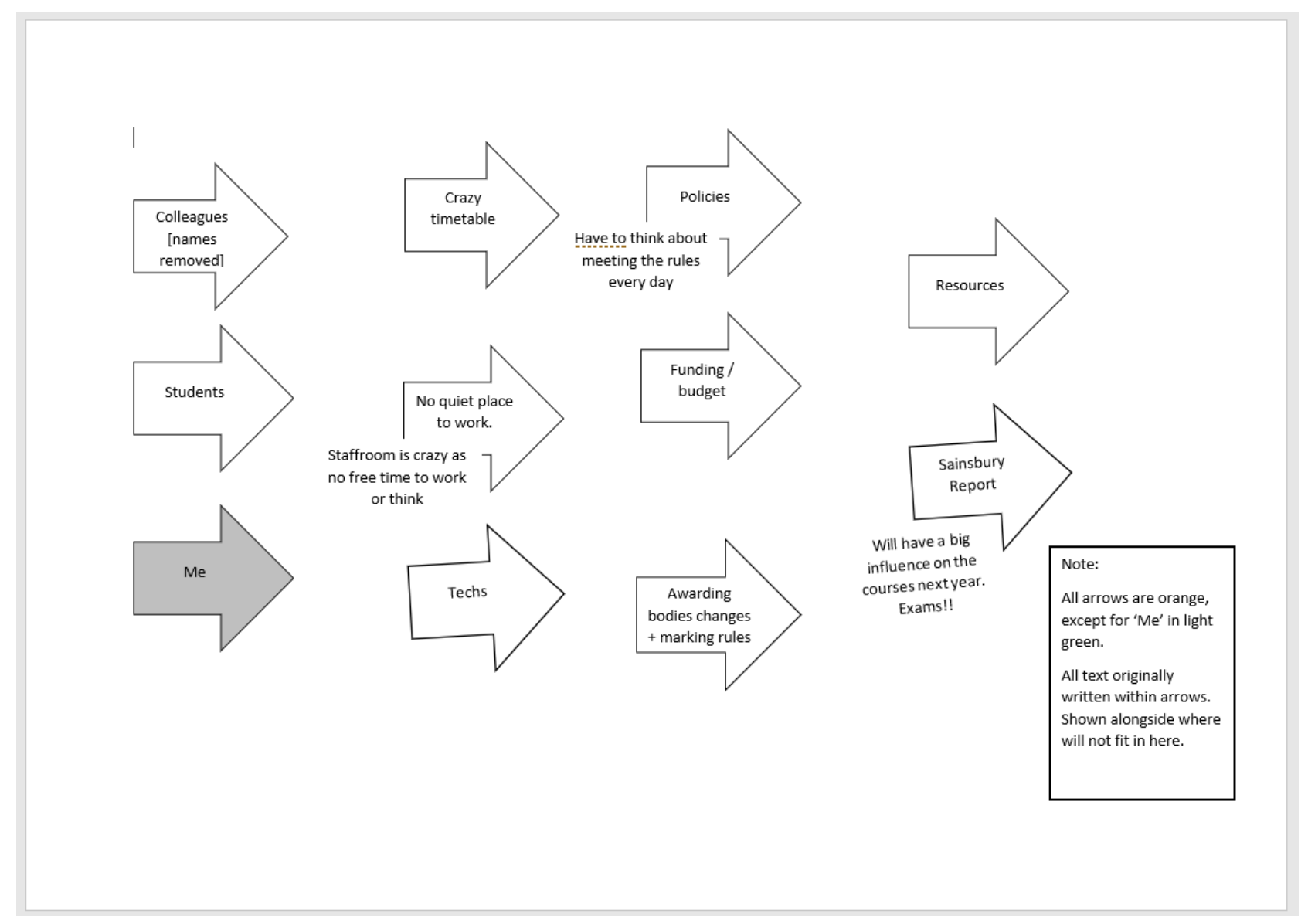

Figure 3. Kerry's Pictor chart

Kerry chooses to start her discussion of her chart by focusing on colleagues: 'so I've put on there $[\ldots]$ the things like that's important to myself $[\ldots]$ obviously the relationship between colleagues'. Her use of the word 'obviously' is telling here, as it suggests that the centrality of colleagues to her role as a teacher is entirely self-evident, perhaps echoing Leah's rhetorical question, 'They're the ones who understand, aren't they?' She also addresses the relative position of the arrows on her chart:

I put them [...] my colleagues and my students above myself in a like professional way, because if I didn't have my students I wouldn't have a job, and if I didn't have colleagues I wouldn't have anyone who [sic] to have that relationship with.

While her justification of the importance of colleagues appears a somewhat circular argument, the deeper inter-connectedness of students, colleagues and her professional role are brought out in her following explanation of what colleagues enable her to do: 
To discuss different problems about what's happening or the changes that are coming in with the Sainsbury's Report cos from next year students are going to have exams, we've got new specs to be writing, and working to. So that's going to be a big overhaul and a big change, especially for our department.

Although Kerry has placed the Sainsbury Report and the impact of its recommendations at some distance from both students and colleagues on her chart, in her spoken interpretation of the chart, these are integrated, colleagues playing a central role in the process of working out how best to respond to external shifts in policy, while meeting the needs of students. Similarly, the 'Techs' (technicians) on her chart appear unconnected to her colleagues and in an indeterminate relationship to herself, yet her explanation of their significance focuses explicitly on relationships:

whereas before when I was a technician and teaching I was I knew what was changing so it's almost like I'm having to take a step back to ask permission for a job that I'm highly qualified to do. I mean it's working alright because we've got some good technicians and we have got a really good rapport. So when they come to me 'well, actually Kerry this needs doing, how would you, how would you have done it?' we do have a [pause] type of like team meeting so we can advise them, because they're quite new to the college.

It is clear from this extract that Kerry is still negotiating the transition from technician to teacher and the changed relationship with the existing technicians that this involves. She is struggling to let go of responsibilities she previously held (having to 'ask permission for a job that I'm highly qualified to do') and to establish a new type of relationship with these colleagues, some tension suggested by her insistence that 'it's working alright $[\ldots]$ and we have got a really good rapport'. The extract also conveys her move into a role where she feels able to 'advise' and mentor others, who are now in a more novice position than herself, being 'quite new to the college'.

The complexity of the analysis that this spoken data allows is not suggested by a reading of the chart in isolation. It appears that some participants find it easier than others to conceive of their role and the influences on it in their totality, creating a 
cohesive representation of these inter-related parts. For others, the selection and placement of the arrows appears more random, yet the chart still acts as a prompt for identification and discussion of the practices in which they participate. A more extensive study would be needed to explore reasons for this contrast and whether it reflects differences external to the individual or lying within their cognitive structures and dispositions, or perhaps a combination of these factors.

In relation to the first two elements of my conceptualisation of learning, practices and participation/reification, my justification of the validity of this methodological tool has depended on the acceptance that the spoken data offers insights into the practices in which the participant engages and the nature of their participation. In Hammersley's terms, the data is being used to provide both 'witness accounts' (of what the participants actually do) and to reveal their 'orientations' towards this (2008, 91 Ref list). But the use of the Pictor data to explore the negotiation of meaning required by the participation in practice is more methodologically complex. It involves a focus on the 'constructional or discursive work' (ibid., 91) in which the participant is engaged in the interview itself, through which the spoken data is produced.

When Leah seeks to navigate the tensions between enacting instructions from senior managers and maintaining a positive working relationship with her students her account operates on two levels: first, her attempts to explain her practice are highly revealing of the efforts she makes to experience this practice as meaningful. This involves (re)organising and (re)framing the mental concepts she holds, allowing her to act in a principled way ('what they say goes, that's what you have to adhere to' versus 'I think they do forget sometimes the actual needs that the learners may have'). This is clearly a difficult process which is intricately bound up with the web of organisational practices of which she is a part. Second, within the interview itself a process of 
meaning-making takes place, the participant attempting to reach secure understandings of the practices she describes. This is evident in the shifts in direction in her spoken account, offering one possible interpretation and then another, before seeking to reconcile the two ('it's not as cut and dry. I do sometimes think they forget that. But then, they are here to learn, they've enrolled on a course'). It could be argued, therefore, that the negotiation of meaning is not so much a feature of her role as a teacher, as a product of the interview situation. This critique is not specific to the use of the Pictor tool, but relevant to all findings deriving from interview data. The socio-cultural interaction inherent in the interview situation inevitably mediates the issues discussed. Yet, as Hammersley argues, this is both constraining and enabling in terms of the interpretations it allows. It is incumbent on the researcher to acknowledge that the interview data cannot provide a transparent window on the practices and context in question. But the negotiation of pressures and tensions evident in the interview data provide insights into how these work on the individual. Attempts at meaning-making, stimulated by the Pictor chart's need for explanation, are an illuminating element of the interview data.

While the negotiation of meaning foregrounded here may not appear as significant or concrete as the type of learning suggested in my research questions (in particular, RQ2: What do FTs learn? How do they learn it?) it goes beyond the technical and morally vacuous notion of learning inherent in what Biesta terms a discourse of 'learnification' $(2009,36)$. Indeed, it appears to align more closely with Biesta's three tenets of education: qualification, socialisation, and subjectification. The negotiation of meaning in which the participant engages qualifies her in enabling her to 'do something', that is to carry out her role as a teacher; it also involves socialisation, in that she seeks to adapt to the culture of her institution; finally, she is clearly working to 
define herself as an autonomous subject. This educational process is taking place in and through the practices demanded by the workplace. It remains to be seen whether the type of education the workplace facilitates in my study has the moral value Biesta ascribes to 'good education' (2009).

\section{Conclusion}

Informal learning in the workplace is a problematic object of study and requires careful operationalisation and appropriate methodological tools in order to capture it systematically. Learning is conceptualised here as the negotiation of meaning necessitated by participation in practice, establishing the three interconnected dimensions of practice, participation/reification and meaning-making as theoretical markers through which the concept of learning may be operationalised. While the use of semi-structured interviews and document analysis as part of a case study methodology allow the researcher to explore the practices in which the interviewee participates, the tool of visual elicitation offers many additional advantages: it encourages the participant to identify aspects of their experience that might otherwise be overlooked or deemed undesirable; it empowers the participant by allowing them to lead the dialogue and provide their own constructs of concepts and events; it also facilitates the interview process, playing the role of a 'third party' in the conversation (Banks 2007, 65).

When selecting a visual elicitation tool, it is important to consider the fit between this and the research question(s) it is designed to address (Bravington and King 2018). The Pictor technique, as a graphic elicitation tool, is appropriate in the context of this study because it enables relationships to be explored, not just between the participant and other people or things, but between these elements themselves. This allows the former in-service trainee teacher to remain firmly situated within the context 
of the organisation in which they work and the policy context beyond this, without imposing the assumptions of the researcher.

But the key question posed in this article is the extent to which the Pictor technique is capable of capturing the former trainee's learning. Analysis of data from one Pictor interview suggests that it has significant methodological value in relation to all three dimensions of the theory of learning outlined above, although the visual data in particular must be approached with caution. First, the tool helps to make aspects of the practices in which the former trainee participates explicit, by prompting the participant to explain elements of their everyday experience that might be deemed too familiar or trivial to mention in a conventional interview situation; while it is acknowledged that the application of the tool may itself influence the artefacts identified, this threat to the validity of the findings is diminished through the analysis of the spoken data in conjunction with the visual data, as shown through consideration of a second interview and chart; participant explanations shed light on the forms their participation takes. Finally, the technique works on two levels to expose the process of meaning-making engaged in by the former trainee: first, the on-going attempt to make sense of their role and experiences as a teacher within their institution; and second, the process of questioning, defining and reaching understandings that extends into the Pictor interview itself.

The key limitation of the analysis presented in this article is the small amount of data used. For this reason it is presented as a methodological exploration, rather than a discussion of findings. However, it does suggest wider applications of the Pictor technique in contexts where the focus is on situated practice and in particular on learning through practice. 


\section{Disclosure statement}

There is no potential conflict of interest known to the author.

\section{References}

Avis, J. and A-M Bathmaker. 2006. "From Trainee Teacher to FE Lecturer: Trials and Tribulations." Journal of Vocational Education and Training 58 (2): 171-189.

Banks, M. 2007. Using Visual Data in Qualitative Research. London: Sage.

Beckett, D. and P. J. Hager. 2002. Life, Work and Learning: Practice in Postmodernity. London: Routledge.

Biesta, G. 2009. "Good Education in an Age of Measurement: On the Need to Reconnect with the Question of Purpose in Education." Educational Assessment, Evaluation and Accountability 21 (1): 33-46. https://doi.org/10.1007/s11092-008-9064$\underline{9}$

Billett, S. 2002. “Toward a Workplace Pedagogy.” Adult Education Quarterly 53 (1): 27-43.

Boud, D., and H. Middleton. 2003. "Learning from Others at Work: Communities of Practice and Informal Learning." Journal of Workplace Learning 15 (5): 194-202 https://doi.org/10.1108/13665620310483895.

Braun, A., S. J. Ball, M. Maguire and K. Hoskins. 2011. "Taking Context Seriously: Towards Explaining Policy Enactments in the Secondary School." Discourse: Studies in the Cultural Politics of Education 32 (4): 585-596.

https://doi.org/10.1080/01596306.2011.601555

Bravington, A., and N. King. 2018. "Putting Graphic Elicitation into Practice: Tools and Typologies for the Use of Participant-Led Diagrams in Qualitative Research Interviews." Qualitative Research, O(0), 1-18. https://doi.org/10.1177/1468794118781718

Brennan Kemmis, R. and A. Green. 2013. "Vocational Education and Training Teachers' Conceptions of their Pedagogy." International Journal of Training Research 11 (2): 101-121.

Chase, S.E. 2011. "Narrative Inquiry: Still a Field in the Making." In The Sage Handbook of Qualitative Research edited by N. Denzin and Y.S. Lincoln, 421-434. Thousand Oaks: Sage.

Colley, H., D. James, M. Tedder and K. Diment. 2003. "Learning as Becoming in Vocational Education and Training: Class, Gender and the Role of Vocational Habitus." Journal of Vocational Education and Training 55 (4): 471-96. 
Dixon, L., A. Jennings, K. Orr and J. Tummons. 2010. "Dominant Discourses of PreService Teacher Education and the Exigencies of the Workplace: An Ethnographic Study from English Further Education." Journal of Vocational Education and Training 62 (4): 381-393.

Eraut, M. 2004. "Informal Learning in the Workplace." Studies in Continuing Education 26 (2): 247-273.

Education and Training Foundation (ETF). 2018. Initial Teacher Education in FE2015/16. https://www.et-foundation.co.uk/research/initial-teacher-education-provisionin-fe-and-skills/

Fuller, A., H. Hodkinson, P. Hodkinson, and L. Unwin. 2005. "Learning as Peripheral Participation in Communities of Practice: A Reassessment of Key Concepts in Workplace Learning." British Educational Research Journal 31 (1): 49-68 https://doi.org/10.1080/0141192052000310029.

Goodley, D., R. Lawthom, P. Clough and M. Moore. 2004. Researching Life Stories: Method, Theory, and Analyses in a Biographical Age. London and New York: RoutledgeFalmer.

Hammersley, M. 2008. Questioning Qualitative Inquiry: Critical Essays. London: Sage.

Hughes, J., N. Jewson and L. Unwin. 2007. Communities of Practice: Critical Perspectives. Florence: Routledge.

King, N., A. Bravington, J. Brooks, B. Hardy, J. Melvin and D. Wilde. 2013. "The Pictor Technique." Qualitative Health Research 23 (8): 1138-1152.

King, N. and C. Horrocks. 2010. Interviews in Qualitative Research. London: Sage.

Lave, J. and E. Wenger. 1991. Situated Learning: Legitimate Peripheral Participation. Cambridge: Cambridge University Press.

Lingfield, R. 2012. Professionalism in Further Education. Final Report of the Independent Review Panel.

https://www.gov.uk/government/publications/professionalism-in-further-educationfinal-report-of-the-independent-review-panel.

Mannay, D. 2016. Visual, Narrative and Creative Research Methods: Application, Reflection and Ethics. Abingdon: Routledge.

Mason, J. 2002. Qualitative Researching. London: Sage.

Maxwell, B. 2014. "Improving Workplace Learning of Lifelong Learning Sector Trainee Teachers in the UK." Journal of Further and Higher Education 38 (3): 377399.

May, T. 2001. Social Research: Issues, Methods and Process. $3^{\text {rd }}$ ed. Maidenhead: Open University Press. 
Miles, M. B. and A. M. Huberman. 1994. Qualitative Data Analysis: An Expanded Sourcebook. 2nd ed. Thousand Oaks and London: Sage.

Ofsted. 2015. Initial Teacher Education Inspection Handbook. London: Ofsted.

Orr, K. 2012. "Coping, Confidence and Alienation: The Early Experience of Trainee Teachers in English Further Education." Journal of Education for Teaching:

International Research and Pedagogy 38 (1): 51-65.

Patton, M. Q. 2002. Qualitative Research and Evaluation Methods. 3rd ed. Thousand Oaks and London: Sage.

Pring, R. 2000. Philosophy of Educational Research. London: Continuum.

Rose, G. 2016. Visual Methodologies: An Introduction to Researching with Visual Materials $4^{\text {th }}$ ed. London: Sage.

Scott, D. 2010. Education, Epistemology and Critical Realism. Abingdon: Routledge.

Society for Education and Training (SET). 2018. Gaining QTLS. https://set.etfoundation.co.uk/professionalism/gaining-qtls/.

Sfard, A. 1998. "On Two Metaphors for Learning and the Dangers of Choosing Just One.” Educational Researcher 27 (2): 4-13.

Springbett, O. 2015. "Enacting Professional Identity: An Exploration of Teacher Educators' Entanglement with Educational Technologies in FE.” PhD diss., University of Lancaster.

Stake, R. E. 1995. The Art of Case Study Research. Thousand Oaks: Sage Publications.

Tummons, J. 2016. "Very Positive' or 'Vague and Detached'? Unpacking Ambiguities in Further Education Teachers' Responses to Professional Standards in England." Research in Post-compulsory Education 21 (4): 346-359.

Wenger, E. 1998. Communities of Practice: Learning, Meaning and Identity. New York: Cambridge University Press.

Wenger-Trayner, E., M. Fenton-O'Creevy, S. Hutchinson, C. Kubiak, and B. WengerTrayner, eds. 2015. Learning in Landscapes of Practice: Boundaries, Identity, and Knowledgeability in Practice-Based Learning. London: Routledge.

Yin, R. K. 2009. Case Study Research: Design and Methods. $4^{\text {th }}$ ed. Thousand Oaks: Sage. 